\title{
Linguistic Levels of Translation: A Generic Exploration of Translation Difficulties in Literary Textual Corpus
}

\author{
Magda Madkour \\ College of Languages and Translation, Al-Imam Mohammad Ibn Saud Islamic University, Saudi Arabia \\ Email: magdasilver@yahoo.com
}

Received: 26-05-2016

Published: 01-11-2016
Accepted: 05-08-2016

doi:10.7575/aiac.ijalel.v.5n.6p.99
Advance Access Published: September 2016

URL: http://dx.doi.org/10.7575/aiac.ijalel.v.5n.6p.99

\begin{abstract}
This case study research was based on a generic exploration of the translation problems that graduate students face in literary translation. Literary translation is fundamental to translation programs at higher education due to the upsurge that has occurred in publishing classical and modern literary works from various cultures. However, literary texts have special characteristics that make the process of transferring them from one language into another a daunting task. Translating literary texts is difficult even for professional translators because misinterpreting the messages of the source texts can lead to distorting the aesthetic aspects of the literary work. Students need to learn various linguistic levels of literary translation as well as strategies and methods of translation. Learning the linguistics levels of translation necessitates providing adequate training that is based on enhancing students' cognitive abilities. Cognitive-based translation training helps students learn the procedures of solving the problems of translating sound and literary devices. Cognitive approaches are relevant to the translation process since cognition implies mental activities that students can use to understand and synthesize the literary text, and reconstruct it creatively. Therefore, the current study aimed at examining the relationship between cognitive teaching methodologies and students' performance in literary translation. To examine this relationship, qualitative and quantitative data was collected from graduate students at the College of Languages and Translation at Imam Mohammed bin Saud Islamic University (IMAMU University), Riyadh, Saudi Arabia. In addition, corpus data was gathered from authentic literary texts including, novels, short stories, and poetry, to investigate the effect of linguistic analysis and cognitive strategies on the quality of literary translation. Quantitative data was analyzed using the Statistical Package for the Social Sciences (SPSS), and qualitative data depended on the software NVivo. The results of data analysis indicated a correlation between using cognitive teaching methodology and students' performance in literary translation. The themes that emerged from the qualitative analysis referred to topics related to causes of translation problems, including lack of experience in the field of literary translation; weakness in literary translation skills; and challenges in interpreting literary devices and eloquence. Data analysis revealed that these problems were due to using traditional teaching methods that were based on giving lectures and direct instructions, and rote learning. The emergent themes concerning ways of resolving these problems include the importance of employing cognitive methods to stimulate students' creative abilities, and motivate them to improve their analytical and critical thinking. The discussions, presented in the literature review of the present study, focus on five issues: the linguistics levels of literary translation; the characteristics of literary texts; the problems of translating literary texts; the main principles of the cognitive method which makes it appropriate for teaching literary translation; and the relationship between literary translation theories, cognition, and creativity. The research recommendations highlight the importance of bridging the gap between translation theory and practice to provide strategies for solving the problems of translating literary texts. The recommendations also include the procedures for integrating Newmark's translation theory into cognitive taxonomies to enhance students' knowledge, and help them acquire refined skills for translating literary texts efficiently.
\end{abstract}

Keywords: cognitive teaching methodologies, linguistic analysis, literary translation, Newmark translation theory

\section{Introduction}

Translating literary texts is difficult because it challenges translators to use cognitive and metacognitive skills to understand ambiguities, connotation, and symbolism. Literary styles also vary depending on each writer's creativity. Therefore, having sensitivity to literary language, and ability to reveal and re-create the work of art helps translators to translate creatively. Research (Barnstone, 1995; Nurmi, 2016; Parrish; 2006; Rojo, 2015; Schwieter, \& Ferreira, 2014; Shreve, \& Angelone, 2010) indicated that artistic translators contribute to the development of translation as an art of revelation, a shift from darkness into light, making the unknown message of the source texts known to the readers of the target languages. To perform such a challenging task, graduate students who will become translators should be trained to enhance their creativity, and refine their skills in classroom environments that help them improve their cognitive abilities. Literary texts, which include fiction such as novels, short stories, folktale, drama, poetry, ballads, sagas, biographies and autobiographies, and children literature have special characteristics and creative messages that make them unique. In this respect, research (Baker, 2000; Boase-Beier, 2011; Chanda, 2012; Larson, 1998; Lihua, 2014; 
Munday, 2012; Newmark, 1988; Stubbs, 2001) indicated that misinterpreting the author's message leads to distorting the aesthetic value of literary texts. Achieving high quality translation requires understanding and analyzing various linguistic levels of literary texts. Bassnett (2002) believed that translatability is connected to human experience in spite of the fact that the basic units of two languages are not always comparable, and that communication can be achieved when the author's message is understood even in a situation different from the original text. Sapargul and Sartor (2010) asserted that using linguistic meta-level analysis helps in applying certain effective strategies such as expansion and subtraction to make untranslatable parts of poetry translatable. Similarly, Pantopoulos (2012) emphasized that efficient translators leave personal marks on the text through their stylistic and semantic choices. In this respect, research (Dean, 2010; Howlett, Ferreira, \& Blomfield, 2016; Moghadas \& Sharififar, 2014; Shreve \& Angelone, 2010; Yingxuek 2013) provided evidence that teaching cognitive approaches had positive impacts on students' performance. Cognitive approaches are relevant to the translation process since cognition implies mental processes that students can use not only to understand and synthesize the literary text, but also to reconstruct it creatively. Thus, the current research examined the effect of using cognitive methodologies on students' creativite translation.

\subsection{Problem Statement}

The present research was based on a case study to identify the problems that graduate students encountered when translating literary texts. Graduate students complained that teachers did not train them to translate creatively. They complained that translation courses at the College of Languages and Translation, IMAMU University, are based on using traditional teaching methods which are ineffective. They also emphasized that using traditional teaching strategies that depend on general lectures and direct instruction did not help them to solve the problems of literary texts efficiently. Evidence from data collection indicated that students' performance was weak. Data also revealed that teaching methods affected the quality of their translation. Additional evidence from previous research (Bransford, Brown, \& Cocking, 2000; Schwieter, \& Ferreira, 2014; Treffinger, Schoonover, \& Selby, 2012) showed that ineffective instruction techniques impacted students' performance negatively. Research (Baker, 2000; Barnstone, 1995; Chanda, 2012; Lefevere, 1992; Munday, 2012; Newmak, 1988; Rojo, 2015; Stubbs, 2001) also indicated that translating literary texts is difficult because failure in conveying the author's message can result in distorting the creative features of the literary work. Such research affirmed that cognitive teaching approaches are relevant to the translation process since cognition requires the enhancement of mental activities that students need to use to understand, analyze, synthesize and reconstruct the literary text adequately.

\subsection{Purpose Statement}

The purpose of this case study research was to examine the impact of using cognitive teaching methods on students' training in literary translation. The study focused on providing statistically significant relationships between cognitive methodologies and students' performance. Previous research (Moghadas, \& Sharififar, 2014; Scott, 2004; Treffinger, Schoonover, \& Selby, 2012; Wilson, 2005; Yingxue, 2013) pointed to potential solutions for solving the problems of literary translation through enhancing translators' creativity. Research (Nurmi, 2016; Pantopoulos, 2012; Rojo, 2015; Sapargul, \& Sartor, 2010; Van, 2009; Zasyekin, 2010) also emphasized that effective theoretical and methodological approaches of literary translation highlighted the relationship between cognition and creativity. To examine this relationship, the current research depended on collecting qualitative and quantitative data from graduate students at the College of Languages and Translation at IMAMU University. Moreover, corpus data was gathered from authentic literary texts, including novels, short stories, and poetry to conduct generic textual analysis in order to reveal the linguistic levels that affect the process of translation. The analysis of translation problems, which emerged from the linguistic varieties, was conducted using the genre and register models proposed by Biber and Conrad (2009), Eggins (2004), Halliday and Matthiessen (2013). While the problems related to syntax, semantics, and stylistics were addressed from a genre perspective, the strategies for solving these problems depended on Newmark's $(1988 ; 1995)$ translation theory.

\subsection{Significance of the Study}

The significance of this case study is that it provides a model for using various linguistic levels of analysis to reveal the problems of literary texts so that students can apply appropriate translation strategies to solve these problems prior to translating the text. A corpus-based methodology was implemented to explore different stylistic patterns in literary texts. The main purpose of the corpus data was to reveal the effect of linguistic analysis on translating different genres of literary works. This study also shows that an examination of cognitive teaching methodologies can be the base for helping graduate students' acquire advanced skills to improve their performance in literary translation. The present study emphasizes the importance of cognitive-based translation training at higher education. Instead of using traditional strategies that depend on general lectures, teachers can implement cognitive approaches to help students enhance their creativity while translating different literary texts. By linking translation theory with practice, teachers can prepare students to become efficient translators who are capable of conveying both the source text messages and their aesthetic aspects. Hence, this study is a contribution in the field of literary translation since it provides evidence on how translation can transmit literary works of art from one language to another through linking literary translation theories to cognitive teaching methodologies. The present research is also among a few studies at the College of Languages and Translation that applied cognitive theories in teaching literary translation, aiming at helping graduate students to improve their performance and the quality of their translation. 
The current research theoretical framework was based on Newmark's (1988; 1995) theory of translation, Halliday's 1989; 2014) linguistic theory, Biber and Conrad's (2009), and Eggins' (2004) literary theories, and the cognitive theories of teaching that encompass Bloom et al.'s taxonomy (2000). Newmark (1988) believed that translation theory should focus on investigating the relation between thought, meaning, and language. He proposed a dual theory that enhances semantic and communicative methods of translation. Newmark (1981) stated, "There is no one communicative nor one semantic method of translating a text. A translation can be, more or less, semantic or, more or less, communicative, and even a particular section or sentence can be treated more communicatively or less semantically" (p. 40). Halliday's (1985) theory can be used to analyse seven functions of language, which include the sentence, the communicative, the interactive, the personal, the innovative, the creative, and the realistic-descriptive level. Biber and Conrad (2009) proposed three analytical models to compare and describe a wide range of texts, including literary works. These models encompass the perspectives of register, genre and style. Students can use such models as a general linguistic treatment prior to the process of translation. Eggins (2004) introduced a systematic functional linguistic model to integrate Halliday's theory into a social semiotic approach to language, which can help in analyzing the cultural context of literary texts. In this regard, research (Baker, 2005; Bassnett, 2002; House, 2014; Munday, 2012; Pym, 2010; Shirinzadeh \& Mahadi, 2014) showed that translation as a cognitive science involves extensive linguistic and cultural knowledge of the source and target languages. Newmark (1988) suggested different procedures to translate the original literary texts through applying three approaches: the text-centered structuralist model; the author-centered traditional model; and the cognitive reader-centered model. According to research (Baker, 2000; Chanda, 2012; Kussmaul, 1995; Shreve \& Angelone, 2010), a cognitive approach is appropriate for transferring the meanings from the source language because it entails more than a simple reproduction of the original text. Cognitive approaches provide models for translation that depend on mental activities, helping students to analyze complex knowledge, identify the translation problems, and apply suitable strategies to solve the problems. Newmark (1988; 1995) asserted that translating literary texts requires understanding and interpreting the texts through focusing on the textual and the referential levels of the source texts. Conveying the meaning in literary texts is challenging due to the complexity of their creative aspects which include implications, images, connotations, and symbolism. In this respect, Newmark (1988) emphasized that translation theories should provide appropriate procedures such as modulation, compensation, lexical synonymy, transposition, amplification, expansion or reduction, and cultural equivalence to solve the translation problems. In this light, Nida (1964) introduced the dynamic equivalence principle to emphasize the importance of achieving an equivalent effect on the target language readership similar to that produced on the readers of the source text. Moreover, House (1997) analyzed the quality of literary translation in relation to translation equivalence (Catofrd, 1969; Albrecht, 1987, 1990, as cited in House), and the invariance in translation, (Koller, 1992, as cited in House). House (1997) explained that Koller's research contained denotative and connotative equivalence, normative equivalence, pragmatic equivalence, and formal-aesthetic equivalence, which can guide translators while translating works of art. Based on these theories, the linguistic levels of analysis can be conducted using Halliday's (1989) three language functions: ideational; interpersonal, and experiential, and Halliday's (2014) metaphorical modes of expression. Furthermore, analyzing the research on pragmatics, including Reiss' (1971), Reis and Vermeer's (1984), and Reiss, (1989), Newmark (1988) pointed out that such studies were founded on using Buhler three language functions to determine three different textual types: referential; emotive-expressive; and conative persuasive. In harmony with Newmark's research, House (2014) pointed out that the final product of the translation must prove to be of high quality. Therefore, based on this conceptual framework, the process of literary translation that highlights the importance of the aesthetic values can be achieved through a cognitive approach that incorporates three phases: (a) identifying different linguistic levels and functions of the text; (b) discovering the meaning of literary texts through understanding the author's message; and (c) enhancing the mental activities of the translators to reconstruct the implied meaning.

\subsection{Definitions}

The current research includes a number of terms that require specific definitions to understand the conceptual foundation of the study. The following is a list of these terms and their definitions:

\section{Adaptation}

"The freest form of translation, used mainly for plays and poetry; the themes, characters, plots are usually preserved, and the source language culture converted to the target language culture and the text is rewritten" (Newmark,1988, p. 46).

\section{Bloom's Taxonomy}

A cognitive model aims at enhancing higher order of thinking through six cognitive domains: knowledge, comprehension, application, analysis, synthesis, and evaluation (Bloom et al., 2000).

\section{Cognitive Teaching Approaches}

Teaching methodologies that are based on cognition, i.e. using mental abilities to perceive, process, analyze, and evaluate knowledge (University of Kansas, 2015).

\section{Communicative Translation}

"It attempts to render the exact contextual meaning of the original text in such a way that both content and language are readily acceptable and comprehensible to the readership" (Newmark, 1988, p. 47). 


\section{Equivalence}

The closest correspondence in the target language which represents the meaning of a word or phrase in the source language; however it is difficult to achieve formal equivalents between two languages (Nida,1964). The concept of equivalence was discussed by Catford, Baker, House, Jakobson , and Vinay and Darbelnet (as cited in House, 1997), among other theorists.

\section{Equivalent Effect (Dynamic Response)}

Rendering the message of the original text in such a way as to achieve the same effect on the target language readers as it was obtained by the readers of the source language (Nida, \& Taber, 1969)

\section{Free Translation}

"It reproduces the content without the form of the original; it is usually a paraphrase much longer than the original, a socalled 'intralingual translation', often prolix and pretentious, and not translation at all" (Newmark, 1988, pp. 46-47).

\section{Genre}

It refers to the type of texts. The category of genre is useful for the analysis and evaluation processes. Genre connects texts with the macrocontext of the linguistic and cultural community in which texts are embedded (House, 1997). Literary Translation: "The source language grammatical constructions are converted to their nearest target language equivalents, but the lexical words are translated singly, out of context" (Newmark 1988, p.46). Semantic Translation

"It emphasizes loyalty to the original text, and must take more account of the aesthetic value of the source text." (Newmark 1988, p. 46).

\section{Newmark Translation Theory}

"Translation theory is the body of knowledge about the process of translating, and it attempts to give some insights into the relation between thought, meaning, and language; the universal, cultural, and individual aspects of language and behavior" (Newmark, 1995, p.19).

\section{Quality of Translation}

It can be determined by "comparing a set of inherent characteristics with a set of requirements. Only when the inherent characteristics meet all requirements, high level quality is achieved (House, 1979).

\section{Literature Review}

The literature review addresses the research questions which focus on the impact of using cognitive teaching methodologies on students' performance in literary translation. The discussions herein include four issues. The first issue is the linguistic levels of literary translation. The second issue deals with the characteristics and problems of literary texts. The third issue involves an analysis of studies that link translation theory to practice. The fourth issue deals with the application of cognitive approaches for training students become efficient translators.

\subsection{Linguistic Levels of Literary Translation}

The purpose of linguistic analysis is not only to describe or identify the differences between source and target languages, but also to make modifications, when appropriate, to achieve accurate translation. Therefore, linguistic analysis should contain morphological, syntactical, and semantic structures. While morphological analysis helps to describe for translators the internal structures of words and how they can be modified, syntax analysis describes how words that are combined together to create grammatical sentences can be rewritten in the target language. Semantics analysis helps translators to understand clearly the meaning of words and phrases so that they can convey it appropriately. Linguistic analysis is necessary as it guides the translators of literary texts to penetrate into the functional system of source and target languages. Madkour (2011) asserted that students should use their cognitive abilities to conduct linguistic analysis. Research (AlBzour, 2016; Argamon, et al., 2007; Biber \& Conrad, 2009; Eggins, 2004; Halliday, 2014; Martin \& Rose, 2007; Martin \& White, 2005; Stubbs, 2001; ToV Le, \& Le, 2015; Zasyekin, 2010) indicated that linguistic analysis helps to explore stylistic norms of across genres, and investigate factors that are beyond the mechanism of grammatical rules. For example, Halliday (2014) emphasized how linguistic analysis can bridge the gap between cognitively and socially oriented theoretical perspectives. While social theories of language are centered on the communicative approach, the cognitivist theories focus on understanding the conceptualization of language through unit of analysis and language patterns. Hence, deep linguistic analysis requires using cognitive abilities. In the light of this, research (Kenesei, 2010; Grossman, 2011; Gutt, 2010; Schwieter \& Ferreira, 2014; Shreve \& Angelone, 2010) indicated that cognitive approaches require an analytical study of the original texts to understand their phonological, morphological, stylistic, and semantic components. According to Newmark (1988), translating a literary text also requires an analysis of the intention of the text, the translator, and the reader. He believed that transferring the aesthetic values of literary texts must provide an eloquent representation of the messages of the text. In other words, a competent translator should process the literary text using a series of cycles that include comprehension, analysis, synthesis, evaluation, and recreation. Enhancing students' cognitive abilities necessitates gaining knowledge and skills on understanding the characteristics of literary language, identifying the translation problems, implementing proper strategies for solving the problems, and selecting the most appropriate translation method. Applying Newmark's theory $(1988 ; 1995)$ which involves an analysis of the literary text prior and after the translation process, can be successful when teachers use cognitive teaching techniques. Newmark (1988) specified three phases for achieving effective literary translation which include: identification of the translation problems through text analysis, 
implementation of translation procedures to solve the problems, and evaluation of the quality of the translation. Thus, theoretical and methodological studies of the process of translation emphasize translation as a cognitive science. The cognitive aspects of translation link it to cognitive linguistics and psycholinguistics, which are also relevant to the studies of literary texts. This means that translators need to have in-depth understanding of all the linguistic and communicative levels relevant to literary texts. However, linguists have various perspectives about the degree of integration or separateness of language levels. While Chomsky (1957) argued that grammar is independent of meaning, Firth (1957) believed that grammar and meaning are interdependent. Halliday (2014) believed that language has three main functions: the ideational, the interpersonal, and the experiential, which require different levels of analysis. Halliday (1989) proposed seven levels of linguistic analysis based on the functions of language. The seven levels are: instrumental, regulatory, interactional, personal, heuristic, imaginative, and representational. In the light of this, Bassnett (2002) argued that the process of translation occurs at three levels: intralingual translation, or rewording, which is an interpretation of verbal signs in the same language; interlingual translation, which is an interpretation of verbal signs by means of some other language; and intersemiotic translation or transmutation, which is an interpretation of verbal signs by means of signs of nonverbal sign systems. Using levels of linguistic analysis, Sapargul and Sartor (2010) asserted the significance of implementing a comparative literature method by focusing on grammar, vocabulary, and translation practices. Such a method combines Grammar Translation (GT) and Culture Literature Method (CLM) to help students compare and contrast themes and cultural aspects found in the Source Language (SL) and the Target Language (TL). In this connection, Jones (2014) concluded that the linguistic-based strategies of approximation, adaptation and imitation, which are used in translating poetry, are helpful in specifying the untranslatable elements in poetic discourse.

\subsection{Literary Texts Characteristics and Problems}

Literary genres include poetry, drama, novels, short stories, folktales, biographies and autobiographies, children literature, and science fiction. These literary genres are characterized by their own diction, imagery, symbolism, and sound devices including rhymes and rhythms. Literary texts are also characterized by their use of such devices as alliteration, assonance, consonance, metaphors, similes, onomatopoeia, oxymorons, metonymies, and irony. Literature is allegorical with symbols that translators need to understand literally and figuratively. Students should be trained to identify the function of the language, and grasp the implied meaning. Jakobson (1967) identified three main functions of the language: the expressive, the informative, and the vocative. While the informative and the vocative functions are identified in objective texts such as academic textbooks and scientific articles, the expressive function is used in subjective texts such as works of art. Translators should also be aware that diverse genres of literature require different translation strategies. For example, some studies (Baker, 2011; Gee \& Handford, 2013; Landers, 2001; Parrish, 2006; Stubbs, 2001) concluded that discourse prosody requires distinctive skills, knowledge, and mental abilities that allow translators to understand the syntactical components of the literary works, and the implied meanings. Translating poetry, for instance, needs knowledge about meter and rhyme. Metaphors are also an important feature of literary style. Translating metaphors entails the application of specific strategies. Research (Baker, 2005; Bransford, Brown, \& Cocking, 2000; Chanda, 2012; Dean, 2010; Newmark, 1988; Parrish, 2006; Schaffner, 2004; Shi, 2014) discussed the implications of the cognitive approach, strategy of domestication or foreignization when translating metaphors. Venuti (2012) investigated cultural problems in translation, and showed how effective translation strategies helped in solving such problems in a way that influenced the meaning of the target text. Waldau (2010) pointed out that metaphors can be classified as structural or conceptual metaphors, and orientational or ontological metaphors. In this light, Newmark (1988) identified five types of metaphors, which include cliché, stock, recent, adapted, and original. Newmark proposed seven procedures for translating metaphors. While the first procedure is to reproduce the same image in the target language, the second procedure deals with replacing the image in the source language with a standard target language image, which does not conflict with cultural issues. The third procedure involves converting the metaphor into a simile, retaining the image. The fourth procedure is to translate a metaphor or simile by simile plus sense. While the fifth procedure is to convert a metaphor to sense, the sixth procedure involves using the same metaphor combined with sense, in order to enforce the image. The seventh procedure allows the deletion of the metaphor, when it is redundant. Newmark (1988) also noted that translating novels and short stories requires identification of two significant concepts, namely: leitmotifs and the author's key words. Leitmotifs are peculiar to a short story for characterizing a character or a situation. For example, descriptive leitmotifs were used in romantic short stories. In English literature, Dickens used leitmotifs to tag the behaviors of some characters. The authors' key words are important to convey connotations. Literary texts also have cultural 'flavors' and as Enani (200) stated, "the degree of cultural transformation is in fact necessary"(p.52); therefore, literary translation requires continual adjustments, using strategies such as omission, addition, modulation, replacement, naturalization, to achieve a high quality of translation. Lefevere (1992) pointed out that in a comparative literature context, translators need to understand the cultural status of the source text so as to look for relevant analogies in the target literature. Therefore, translators need to use the manipulation strategy, i.e. rewriting the message of the source text.

\subsection{Linking Translation Theory to Practice}

According to Newmark's theory $(1988 ; 1995)$, an attempt to link theory to practice when translating literary texts necessitates a distinction between metaphrase, i.e. literal translation, and paraphrase, i.e. free translation. In this respect, Dryden (1631-1700) defined translation as merging these two modes when choosing the equivalent expressions in the target language. Dryden (1987) indicated that the translator's task should not be restricted to transferring the aesthetic language by selecting artificial words that do not convey the meaning. Similarly, Newmark (1995) believed 
that translation is a science as well as an art, which means that translating literary texts involves gaining knowledge about literature, its movements, historical roots, social and cultural settings, and philosophical and psychological issues. Newmark's (1988) taxonomy of translation strategies includes: transference, which refers to the process of transferring an SL word to a TL word; naturalization, which conforms the SL word first to the normal pronunciation, then, to the normal morphology of the TL; cultural equivalent, which intends replacing a cultural word in the SL with TL word; functional equivalent, which is the procedure used to translate cultural terms; descriptive equivalent, which is the procedure used to explain the meaning in several words; componential analysis, which compares SL word with TL word which has a similar meaning; lexical synonymy, which means to translate by a near TL equivalent. Other linguistic levels of analysis include through-translation, which is the literal translation of common collocations such as components of compounds; shifts or transpositions, and it involves a change in the grammar from SL to TL, e.g., change from singular to plural or active into passive. Another strategy is modulation, which occurs when the translator reproduces the message of the original text in the TL text in accordance with the norms of the TL. In addition, the strategy of compensation is used when loss of meaning in one part of a sentence is compensated in another part. Furthermore, according to Nida (1969), the main purpose of translation is to achieve equivalent effect, i.e. to attain the same effect on the target language readership as it was achieved on the readership of the source language. He described the concept of equivalence as the 'functional or dynamic equivalence'. Dynamic equivalence requires the translators' imaginative and intuitive talents. Applying the principle of dynamic equivalence is feasible in translating literary texts because most of the themes of literary works are descriptions of human experiences which have universal elements that are applicable to the target language readership. As such, the translator's task is to re-establish the equilibrium between meaning and form while translating literary texts. A creative translator must also present the art of rhythms and symbolism to convey the beautiful meanings implied in poetic texts. In this respect, Baker (2005) asserted that the process of contextualization is essential not only to reveal what is implied in the text, but also to expose its relation to reality and to the readers, creating a dynamic response with its context and culture. Chanda (2012) explained that in literary translation, understanding metaphors is important, and that the process of translation begins with identifying the relationship between sense and reference in the source text, such as the metaphor 'worth her weight in gold. A semantic analysis is required to understand the context that determines the meaning of the metaphor beyond the literal meaning. In accordance with this, Jakobson (2000) stated, "the meaning of any linguistic sign is its transfer into a further alternative sign" (p.139) Regarding the application of literary theories, Lefevere (1992) suggested seven methods for translating poetry, which include phonemic translation, metrical translation, rhymed translation, blank verse translation, poetry-to-prose interpretation, and literal translation. The difference between phonemic translation and metrical translation is that phonetic translation focuses on the sound devices of the source text while metrical translation aims at recreating the original meter in the target language. While a rhymed translation tries to render the rhyme of the original poem into the target text, blank verse translation focuses on conveying the equivalent meaning of the original poem. Poetry-to-prose interpretation communicates the meaning at the expense of the poem structure. Literal translation refers to two ways for interpreting the original poem. The first way is to create a semantically-oriented version of the original poem. The second way is to write an imitation of the original poem making use of only its topic. However, syntactic and lexical adjustments in all these methods of translating poetry are necessary. Jae (2005) believes that proper translation occurs when such adjustments are carried out, and that untranslatability takes place when translators fail to find an equivalence for a word, an idiom, or expression in the target language. Sun (2012) states that cultural connotation is a challenge in translation. Thus, the issue of untranslatability necessitates a continuous effort for achieving readability.

\subsection{Translation Cognitive-Based Training}

Cognitive approaches focus on mental activities that include thinking, understanding, synthesizing, analyzing, and reconstructing the information coherently. Cognitive approaches to translation attempt to explain how minds work so translators can use their mental abilities to grasp implied meanings, identify translation problems, select appropriate solution strategies, and develop translation competence. Research on cognitive approaches to translation asserted that cognitive approaches enhance translators' skills and performance. For example, Risku (2009) used field studies to examine the relationship between cognitive views and quality of translation. Shreve, Lacruz, and Angelone (2010) confirmed the effect of cognitive methods on understanding interferences while involved in the process of translation. Munoz (20110) investigated the relationship between cognition and translation purposes. Rydning and Lachaud (2010) affirmed the effect of cognitive approaches on helping translators solve the reformulation challenge in translation, in terms of reducing polysemy during the phase of comprehension, and enhancing creativity during the production phase. According to Shreve and Angelone (2010), translation and cognition evaluate the act of creation in translation. Teachers need to know that for students to become creative translators, teaching strategies should be based on cognitive approaches to identify students' potentials for promoting their translation skills. However, teachers focus on traditional teaching methods that promote memorization of vocabulary and dictionary skills. Yingxue (2013), suggested using cognitive approaches such as problem- based teaching to help students recognize the typological differences of languages. According to Yingxue (2013), cultural conversion is a creative point that can be enhanced by using cognitive methods. Thus, the main purpose of using cognitive teaching techniques is to help students bring up their sensitivity to source and target languages. In harmony with this view, Kussmaul (1995) confirmed that sensitivity and intuition allow access to creativity. He suggested a four-phase model of creative processing, which embrace preparation; incubation; illumination; and evaluation. Cognitive teaching approaches are compatible with Kussmaul's model since cognition implies the same mental activities that enhance students' creativity. For instance, translating cultural elements in a 
literary work is one of many complicated processes in translation that can be facilitated using cognitive methods to teach literary translation. Literary translation primarily depends on the translators' linguistic abilities, knowledge of works of art, social background, and cultural features of the source text. Therefore, translators' knowledge and skills should be developed through cognitive-based training.

\section{Research Method}

The current research was based on a case study method to investigate the problem of inadequate translation training. Graduate students at the College of Languages and Translation, at IMAMU University, were selected as a case study. A homogeneous focus group of 25 participants shared their real-life experience as translators of literary texts. This group was selected from only the female students who studied three courses in literary translation. The graduate students constantly complained about the recurrent problems associated with literary translation. They mentioned such problematic issues as lack of training, inability to render the aesthetic value of the original texts, difficulties in understanding ambiguities and implicature, and difficulties in producing quality translation. The case study method was appropriate because the purpose of this research was to examine the events of the selected group through identifying the problems based on case investigation. The case study method helped to explore these issues, using textual generic explorations of translation difficulties in literary corpus. According to Creswell (2013), a case study is a research methodology which is founded on an empirical inquiry to examine a problem within its real-life context. Yin (2014) asserted that a case-study research can include quantitative and qualitative evidence, and can benefit from prior development of theoretical propositions. Hence, the present research depended on establishing a rigor for credibility, transferability, dependability, and confirmability, which are four important criteria relevant to case study research, by linking the research problem to the theoretical base of the study and the review of relevant previous studies. 3.1 Participants' Characteristics

To ensure the homogeneity of the participants, the focus group of this case study consisted of 25 female graduate students, selected from the College of Languages and Translation, at IMAMU University, to respond to the questions of the interview. These students studied theoretical and practical courses on translation and linguistics in their master program. They also worked as translators after obtaining their bachelor degree from the same college. They received only one course training in literary translation. The present study also included another sample of 100 graduate students who were selected randomly from the same college to respond to the study questionnaire to provide quantitative data on the causes of the translation problems. All the participants were only the female students who studied English and translation for 7 years at IMAMU University. The participants' profiles revealed that the majority of the participants, with the percentage of $89 \%$ were within the age category of 22 to 27 years old while $11 \%$ were within the age category of 21-24 years old. Regarding the participants' social status, $69 \%$ of the students were married while $31 \%$ were single. While none of the participants studied English or American literature in the master program, they all studied courses on novel, drama, and poetry in their undergraduate program. Only $36 \%$ of the participants worked as translators with local publishers who were involved in publishing literary works.

\subsection{Research Questions}

1).What are the effects of using cognitive-based teaching methodology on graduate students' performance in literary translation?

2). What is the correlation between the independent variables of the linguistic levels of literary texts (lexical, syntactic, and semantic) and the dependent variables of the quality of literary translation (functional adequacy, specialized content, and dynamic equivalence)?

3). How can teachers incorporate literary translation theories into cognitive teaching methodologies?

\subsection{Research Hypothesis}

There is a correlation between cognitive-based teaching methods and students' performance in literary translation. The Null Hypothesis is: There is no relationship between cognitive-based teaching methods and students' performance in literary translation.

\subsection{Procedures}

The sampling of the present study was based on selecting a homogeneous focus group of female graduate students whose language and translation achievements were determined by the average of their academic scores at the end of 2015-2016 academic year. The current study occurred in seven phases. The first phase was selecting the focus group and conducting face-to-face interviews to collect qualitative data about their perceptions, opinions, and attitudes towards their translation training, levels of linguistics analysis, teaching methodologies, characteristics of literary genres, and translation strategies. During this process, the researcher took notes and recorded the interviews. The second phase focused on class observations to evaluate the type of training the participants received in literary translation. The third phase was collecting quantitative data using a questionnaire to identify the translation problems of 100 graduate students who were selected randomly. The fourth phase was based on textual generic explorations of the translation difficulties in literary textual corpus. Textual corpus included the following: (a) texts from novels by Jane Austin, Charles Dickens, Ernest Hemingway, Mark Twain, and Ronald Blythe; (b) short stories by O. Henry, Guy de Maupassant, and E.M.Forster; and (c) poetry by William Wordsworth, Browning, and Eliot. These texts were selected from the curriculum of the College of Languages and Translation, IMAMU University. The fifth phase was collecting additional qualitative data from interviewing the instructors of the translation courses to identify their teaching methodologies. The sixth phase focused on collecting more quantitative data from the participants' archival records of exam results. The seventh phase was selecting samples of literary texts translated by the 25 participants to 
assess their translations' functional adequacy and quality of content. The rationale behind these phases is that the strength of the case study method involves using multiple sources and techniques in collecting data systematically to ensure providing evidence to enhance reliability and internal and external validity. Moreover, collecting data to examine rival explanations, as the case study was proceeding, was necessary to find accurate research evidences throughout the study.

\subsection{Methods of Analysis}

Data analysis techniques depended on mapping the data major concepts, building typologies and themes linked to purpose and unit of analysis. Linking the literature review with data analysis was also necessary to describe the meaning of the data based on the participants' experience as well the theoretical framework and previous research findings. Describing the data relied on labelling the meaning of each participant's experience. Generating meaning from the data depended on clustering the concepts and beliefs of the participants to examine the relationships among the variables, and identifying the intervening variables. This process helped in revealing the emergent themes. Quantitative data was analyzed using the Statistical Package for the Social Sciences (SPSS), and qualitative data

depended on the software NVivo 10. Thus, triangulating, i.e. establishing converging lines of evidence, helped in making the research findings as robust as possible.

\subsection{Corpus Data}

The corpus data included 50 literary texts selected by the researcher, with different genres. The textual analysis of the works of art was descriptive-interpretive. The analysis of the translation problems, which emerged due to linguistic varieties, was based on theoretical perspectives of Biber and Conrad (2009), Eggins (2004), Halliday and Matthiessen (2013) while the strategies for solving the translation problems was dependent on Newmark's (1988; 1995) theory. The textual corpus analysis revealed problems related to syntactic forms, distinctive stylistic features, and pragmatic functions.

\section{Data Analysis Results and Discussions}

Data analysis revealed that the participants had problems in translating drama, novels, short stories, and poetry. Due to lack of cognitive-based translation training, the participants did not acquire the skills of analyzing various linguistic levels of literary texts, which resulted in misinterpretation of the source texts' messages and aesthetic values. The participants had problems in translating imagery, symbolism, sound devices including rhymes and rhythms, and literary devises such as metaphors, similes, puns, emotive verbs, irony, and pathetic fallacies, and onomatopoeia, oxymorons, metonymies, alliteration, assonance, and consonance. Data analysis results showed that lack of experience in translating literary texts, and ineffective teaching strategies were the causes of these problems. The findings of the current study were in harmony with the results of previous research which explored the same problems.

\subsection{Quantitative Data Results}

Judging from the results of the case study analysis, the quantitative data showed that the participants' language levels were based on their GPA. The percentage of students whose language level is advanced (i.e. their grades are between 99-85 out of 100) was $26 \%$ while the percentage of students whose language level is intermediate (i.e. their grades range between $84-70$ out of 100) reached $68 \%$. The percentage of students whose language level is weak (i.e. between 69-60 out of 100) reached 6\%. Students' langue levels are reflected in the results regarding students' abilities for translating literary texts. The percentage of students who have the ability to translate literary texts efficiently is only $12 \%$ while the percentage of students who do not have the ability to translate literary texts efficiently reached $88 \%$. These results are also reflected in the participants' responses regarding the problems they faced while translating literary texts. Figure 1 displays the results.

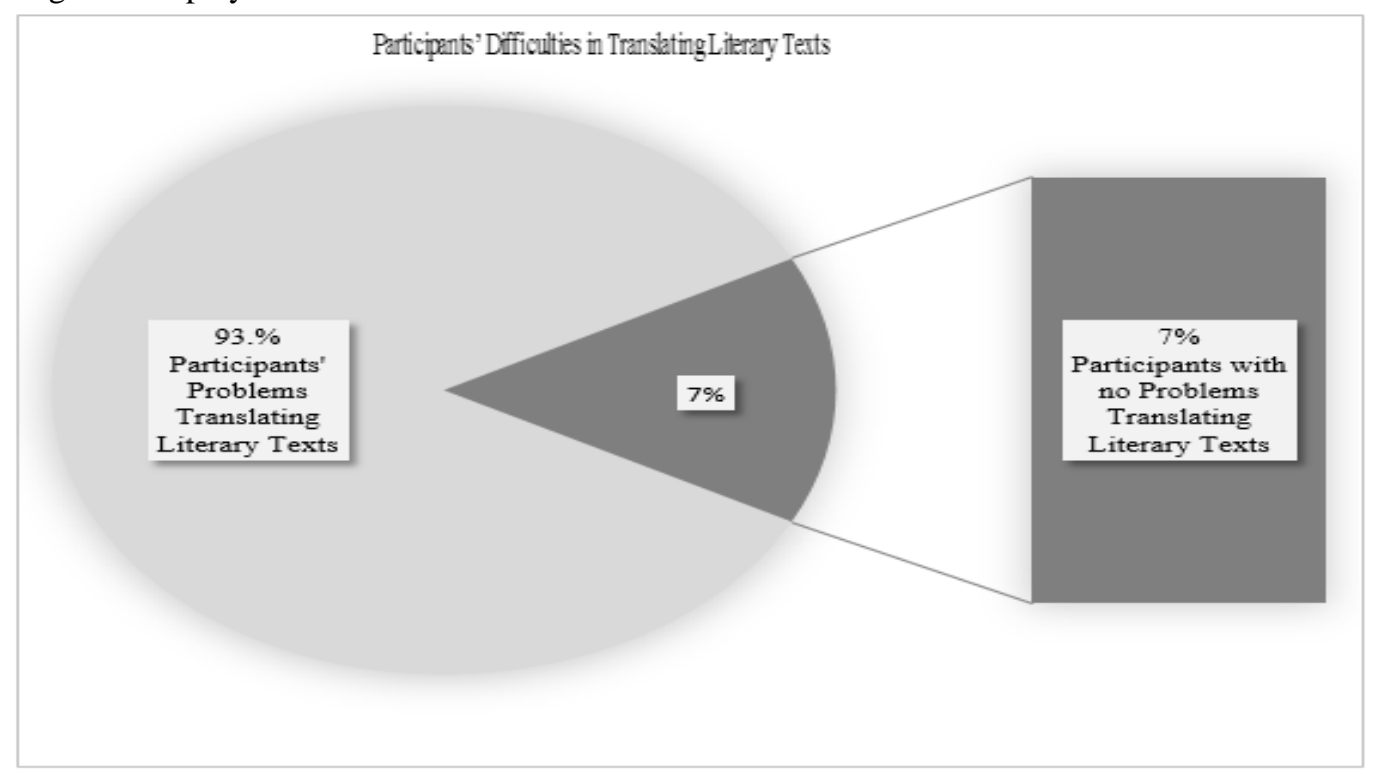

Figure 1. The participants' percentage of difficulties in translating literary texts

As displayed in Figure 1, the percentage of students who have encountered problems when translating literary texts is $93 \%$ while the percentage of students who can translate the literary texts and solve their problems reached $7 \%$ only. The low 
percentage of students who can translate the literary texts and solve their problems is revealed in detail when the participants responded to the question about the type of difficulties they encountered while analyzing the various linguistic levels of literary works of art. Figure 2 shows the results.

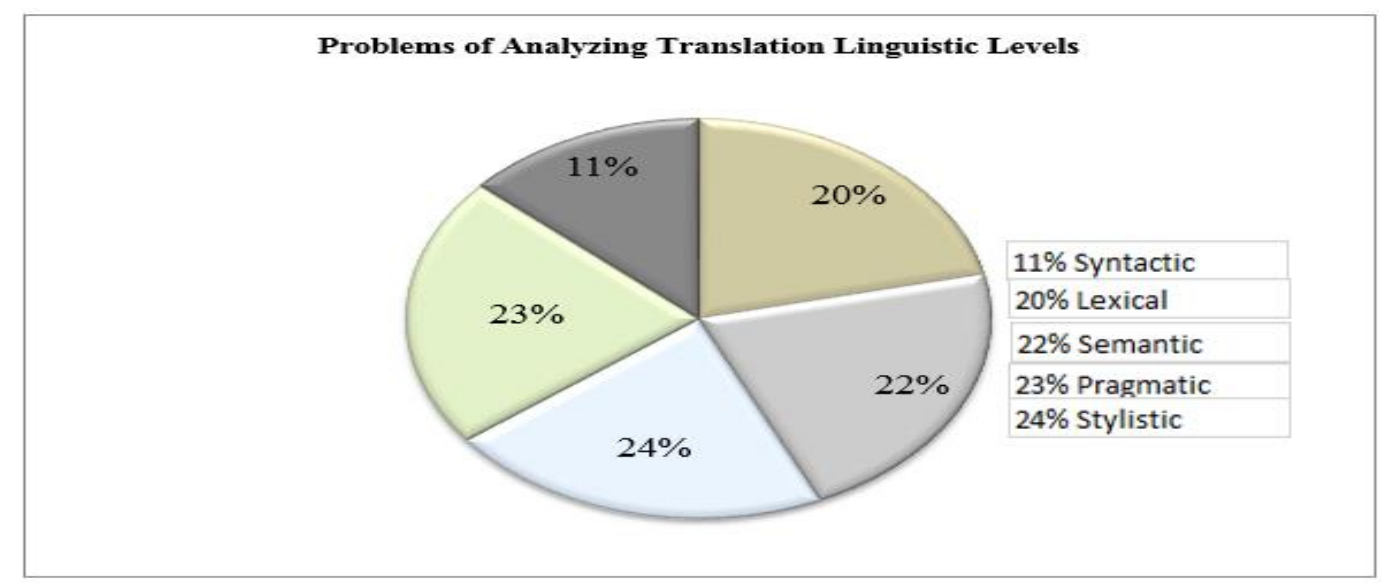

Figure 2. Difficulties of analyzing linguistic levels of literary translation

As shown in Figure 2, the percentage of the participants who faced syntactic problems when translating literary texts reached $11 \%$ and such results were consistent with their grades in grammar. The percentages of the participants regarding lexical, semantic, pragmatic, and stylistic problems reached $20 \%, 22 \%, 23 \%$ and $24 \%$ respectively. These results pointed to the importance of linking various linguistic analysis to translation practice so that students understand the literary text beyond its grammar and vocabulary. The participants also expressed their concerns regarding how to handle literary texts. Figure 3 displays these problems.

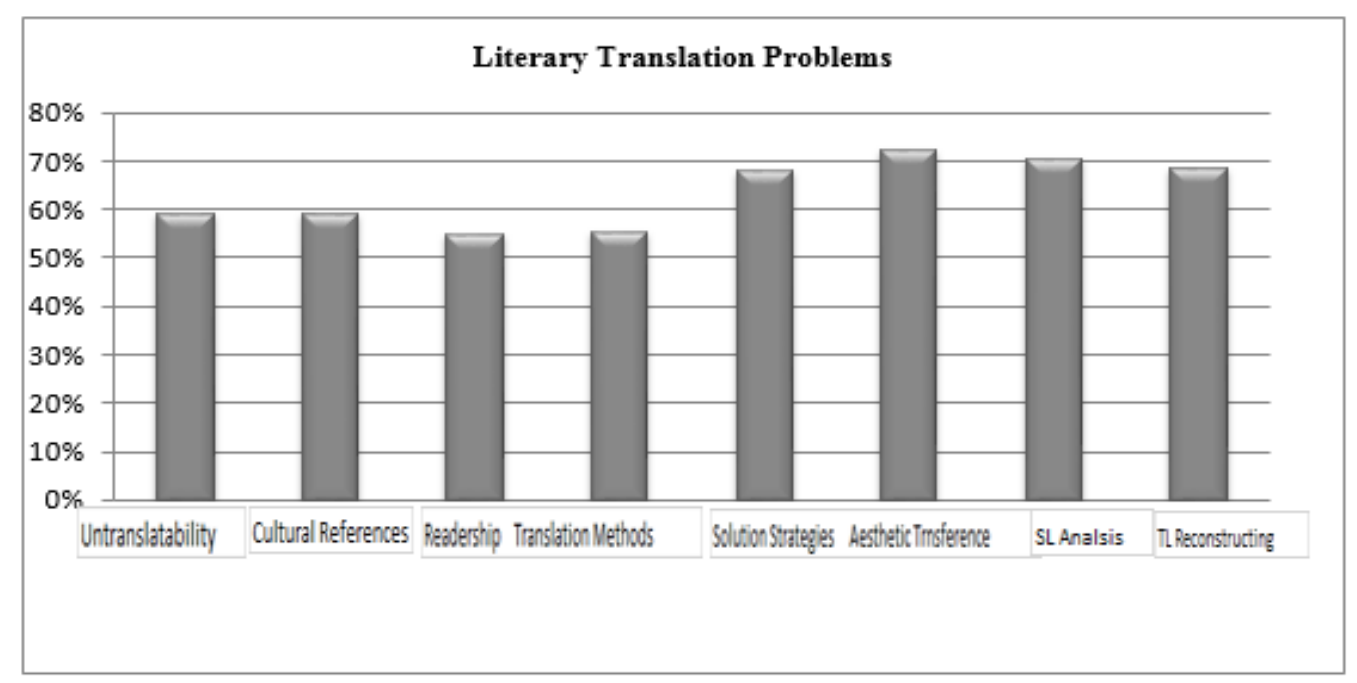

Figure 3. Problems of handling literary texts

As displayed in Figure 4, data analysis results showed the difficulties that the participants encountered with regard to the process of translation itself. The participants had problematic issues regarding readership, translation methods, problemsolving strategies, analysis of the source text, and reconstruction of the target text. The percentage of the readership problem reached $56 \%$ while the percentage of the problem of translation methods reached $57 \%$. The percentage of the problem of applying appropriate translation strategies was $68 \%$. The percentages of the problems of TL reconstruction and SL analysis were $68 \%$ and $70 \%$ respectively. Moreover, the results pointed to problems regarding cultural references, transference of aesthetic value, and untranslatability. The percentage of the problem of cultural references and untranslatability was identical with $59 \%$ while the percentage of the problem of transferring the aesthetic value was the highest among all the problems reaching $72 \%$. The indication of having serious problems to transfer the literary text is shown in the percentage of conveying the aesthetic value of the literary text. The participants had problems translating literary and sound devices, as shown in Figure 4. 


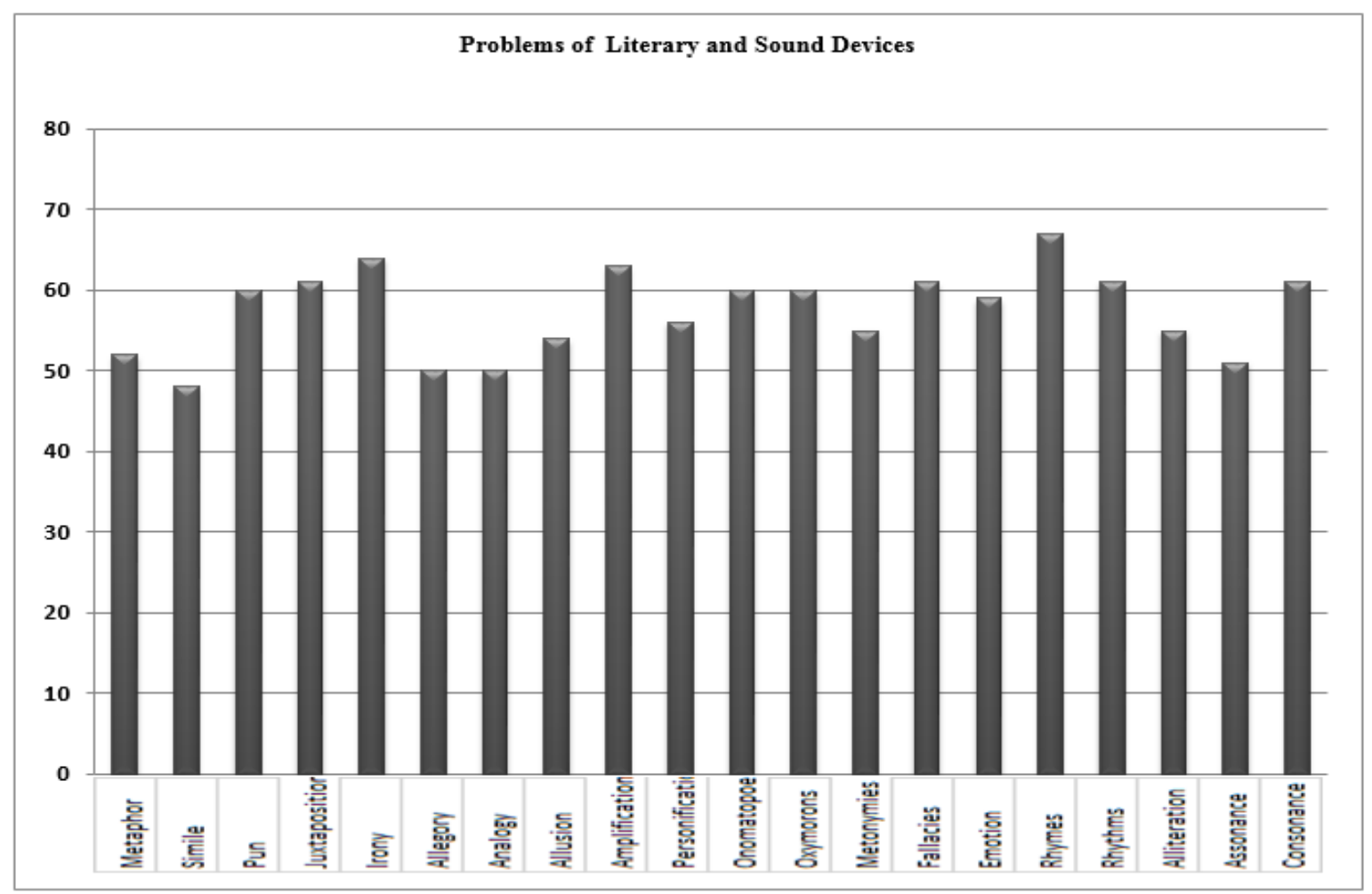

Figure 4. The participants' problems of transferring literary and sound devices

As shown in Figure 4, the participants encountered problems translating literary devices such as metaphors, similes, pun, juxtaposition, irony, allegory, analogy, allusion, amplification, personification, onomatopoeia, oxymorons, metonymies, emotive verbs, and pathetic fallacies. They also faced problems transferring such sound devices as rhyme, rhythm, alliteration, assonance, and consonance. The highest percentages point to the problems of rhyme, irony, amplification, pathetic fallacy, pun, consonance, and juxtaposition reaching $67 \%, 64 \%, 63 \%, 62 \%, 61 \%, 61 \%$, and $60 \%$ respectively. The lowest percentages refer to the problems of simile, allegory, analogy, assonance, allusion, and alliteration, which reached $48 \%, 50 \%, 50 \%, 51 \%, 53 \%$, and 54\% respectively. Such results necessitated an investigation of the type of translation training that the participants received. Figure 5 shows the participants' training problems.

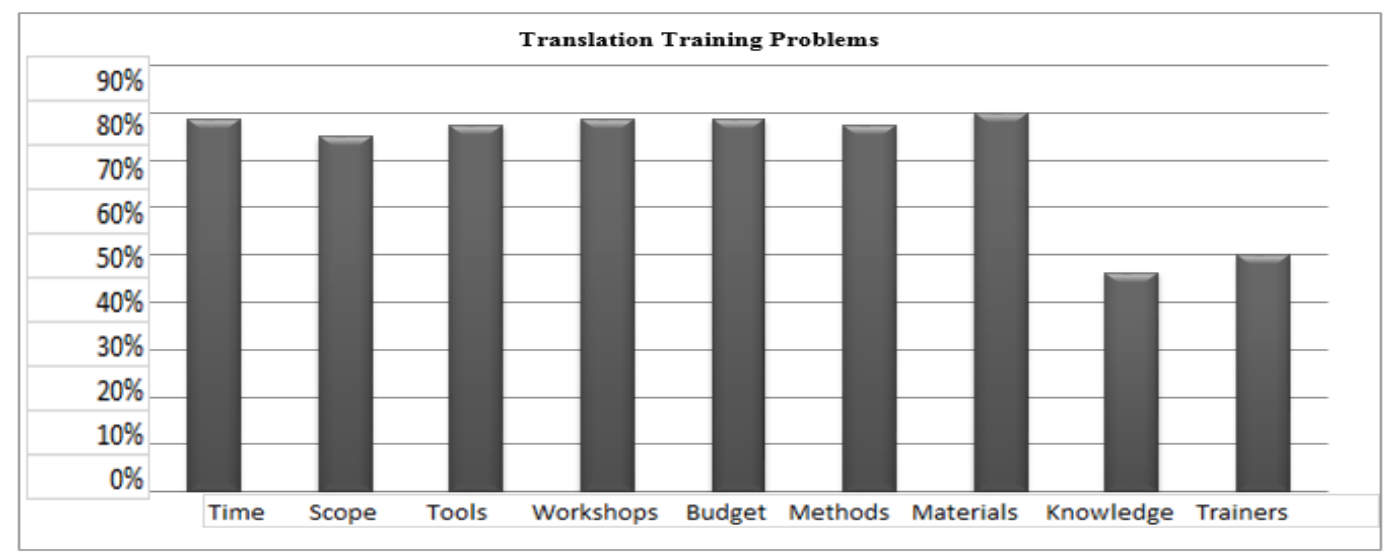

Figure 5. The problems of translation training

Figure 5 shows that the percentage of the participants who reported having problems with translation training materials was $80 \%$ while the percentage of the participants who reported having problems with the time assigned to training was $79 \%$. Another indicator that the participants had problems with the training program was the budget and the methods of training which reached $79 \%$ and $78 \%$ respectively. The percentages of the problems regarding the trainers' knowledge and experience were $47 \%$ and $50 \%$ respectively. Based on the participants' data, these results showed that the teaching methods required modifications. Data analysis also showed that the cumulative percentage of teachers who frequently use traditional teaching methods reached $71 \%$ while the percentage of teachers who sometimes use traditional methods reached $41 \%$, and the percentage of teachers who always use traditional methods reached $28 \%$. Only $6 \%$ of the teachers rarely use traditional methods. Such results indicate that the total number of teachers who use traditional methods is about 94\%., which affects students' skills in dealing with literary translation. This result is also reflected in the frequencies that represent participants' challenges dealing with literary translation. The percentage of students who frequently encountered challenges in translating literary texts reached $29 \%$ while the percentage of students who sometimes encountered challenges in literary translation reached $28 \%$ and the percentage of students who always encountered challenges in translating literary texts reached $40 \%$. Only $3 \%$ of the students rarely encountered 
challenges in literary translation. This result affected students' performance and quality of translation. This result also reveals that a great number of students need to study literature to improve their knowledge and skills, as shown in Table 1.

Table1. Students' need to study various literary genres

\begin{tabular}{llrrrr} 
& & & & Valid & \\
& & Frequency & Percent & Percent & Cumulative Percent \\
\hline Valid & Never & 3 & 3.0 & 3.1 & 3.1 \\
& Rarely & 11 & 11.0 & 11.3 & 14.4 \\
& Sometimes & 28 & 28.0 & 28.9 & 43.3 \\
& Frequently & 28 & 28.0 & 28.9 & 72.2 \\
& Always & 27 & 27.0 & 27.8 & 100.0 \\
Total & 97 & 97.0 & 100.0 & \\
& 3 & 3 & 3.0 & & \\
\hline
\end{tabular}

Table 1 displays the results regarding the percentage of students who need to study different genres of literature. The cumulative percentage of students who frequently need to study literature reached $72 \%$ while the percentage of students who sometimes need to study literature reached $43 \%$ and the percentage of students who rarely need to study literature reached only $14 \%$. This result indicates that lack of knowledge genres of literary works resulted in s having difficulties in translating literary texts. Moreover, the quantitative data analysis also contained calculation of the internal consistency of the questionnaire, and indicated that all the statements in the questionnaire are statistically significant at the level of 0.01 , as $\mathrm{r} \ll 0$, reflecting their consistency. The reliability of the questionnaire was calculated using Cronbach's alpha, and it indicated that the overall Cronbach's Alpha is 0. 808. Table 2 displays the results.

Table 2. Cronbach's alpha results

\begin{tabular}{|c|c|c|c|c|c|c|c|}
\hline$Q$ & f value & if & $\begin{array}{c}\text { Mlean } \\
\text { Diffecremee }\end{array}$ & $Q$ & t tralue & dif. & $\begin{array}{c}\text { Mean } \\
\text { Difforences }\end{array}$ \\
\hline$\overline{Q 01}$ & 39.588 & 98 & 3.795 & $Q 20$ & 17.860 & 96 & 2.794 \\
\hline 202 & 29.066 & 99 & 3.720 & $Q_{21}$ & 21.868 & 93 & 2.915 \\
\hline Q03 & 30.524 & 98 & 3.667 & $Q 23$ & 32.329 & 94 & 3.484 \\
\hline Q04 & 29958 & 96 & 3.515 & $Q 24$ & 26.094 & 95 & 3.063 \\
\hline Qos & 36.146 & 98 & 3.788 & Q25 & 30.425 & 93 & 3.553 \\
\hline Q06 & 24929 & 97 & 3.173 & $Q 26$ & 36.776 & 90 & 4.022 \\
\hline Qo7 & 35975 & 96 & 4.031 & $Q 27$ & 30.388 & 88 & 3.382 \\
\hline Qos & 23.352 & 93 & 3.021 & Q28 & 42.429 & 88 & 4.135 \\
\hline Q09 & 39.191 & 94 & 4.074 & $Q 29$ & 47.407 & 88 & 4.270 \\
\hline Q10 & 43.343 & 98 & 4.162 & $Q 30$ & 42.545 & 87 & 4.239 \\
\hline Q11 & 20.204 & 96 & 2.525 & Q31 & 43.773 & 87 & 4.136 \\
\hline Q12 & 31.055 & 94 & 3.653 & $Q 32$ & 28.022 & 86 & 3.230 \\
\hline Q13 & 35.783 & 94 & 3.705 & Q33 & 39.180 & 86 & 4.103 \\
\hline Q14 & 45.237 & 97 & 4214 & $Q^{34}$ & 40.146 & 78 & 4.025 \\
\hline Q15 & 22246 & 94 & 3.074 & Q35 & 18.962 & 83 & 2.857 \\
\hline Q16 & 32962 & 96 & 3.670 & $Q_{36}$ & 26.222 & 83 & 3.333 \\
\hline Q17 & 19.152 & 93 & 2394 & Q37 & 43.050 & 84 & 4.388 \\
\hline Q18 & 36904 & 92 & 3965 & Q3B & 41.135 & 80 & 4.346 \\
\hline Q19 & 22.660 & 93 & 3.585 & $Q 39$ & 35.923 & 84 & 4.200 \\
\hline
\end{tabular}

As shown in Table 2, the mean differences of the questionnaire items were between 3.063 for question 1 and 4.346 for question 38. The $t$ value was between 17.860 and 47.407. As for the inferential data, the results showed that H1, 'there is a correlation between cognitive-based teaching methodology and students' performance in literary translation', was validated. The researcher used the one sample $t$-test to examine if there is any statistical significance between dependent and independent variables. The results showed that there is a statistical significance at the level of 0.1 as the 2 -tailed significance is less than 0.1 and the $t$ values of the items exceed that of $\mathrm{df}$ (99) which is 2.6264. Thus, the null 
hypothesis is rejected, confirming the positive impact of using cognitive-based transaltion training methodology on students' performance, and affirming the answer to th first question of the present research. Table 3 shows the correlation results.

Tabel 3. The corelation results

\begin{tabular}{|c|c|c|c|}
\hline Question & Corrolation & Question & Correlstion \\
\hline 01 & .065 & 20 & .333 \\
\hline 02 & .406 & 21 & .286 \\
\hline 03 & .372 & 22 & .362 \\
\hline 04 & .555 & 23 & .523 \\
\hline os & .411 & 24 & .033 \\
\hline 06 & .299 & 25 & .430 \\
\hline 07 & .257 & 26 & .292 \\
\hline 08 & .236 & 27 & .126 \\
\hline 09 & .275 & 28 & .362 \\
\hline 10 & .028 & 29 & .509 \\
\hline 11 & .172 & 30 & .253 \\
\hline 12 & .342 & 31 & .166 \\
\hline 13 & .330 & 32 & .398 \\
\hline 14 & .168 & 33 & .291 \\
\hline 15 & .096 & 34 & .342 \\
\hline 16 & .424 & 35 & -.046 \\
\hline 17 & .128 & 36 & .339 \\
\hline 18 & .529 & 37 & .278 \\
\hline \multirow[t]{2}{*}{19} & .336 & 38 & .207 \\
\hline & & 39 & .353 \\
\hline
\end{tabular}

As displayed in Table 3, the inferential data revealed that all the statements in the questionnaire were statistically significant at the level of 0.01 , as $\mathrm{r}<>0$, reflecting their consistency. In addition, the correlation matrix was significant at the level of 0.01 . The qualitative data analysis results, presented herein, were in harmony with the quantitative data analysis findings.

\subsection{Qualitative Data Results}

Using the qualitative software NVivo version 10 for windows (Qualitative Software Research International, QSR, 2016), the interview data was analyzed to construct textual descriptions of core themes, and develop validated invariant constituents. The invariant themes that emerged from the qualitative inferential analysis pointed to topics related to the reasons for the participants' problems, including: (a) applying ineffective teaching strategies for translation training; (b) lack of experience in the field of literary translation; (c) weakness in literary translation skills; (d) inability to analyze different linguistic levels of works of art; and (d) challenges in interpreting literary and sound devices. For example, in responding to the interview questions about methods of training, participant \# 7 expressed her opinion saying, The current teaching methodologies that are based on direct lectures and which lay emphasis on the traditional way of looking up the difficult vocabulary to translate did not help me to translate creatively. When I was translating some short stories by Guy de Maupassant, I was translating literally and was unable to transfer the images and the allegories. I could not transfer the author's message, and the spirit of the work of art was distorted." Moreover, participant \# 13 expressed her concerns stating, I did not receive any adequate training to know the difference between assonance and consonance, or onomatopoeia, and oxymorons, so I had many problems translating some Arabic poems. Translating poetry is important because many local publishers are looking now for publishing Arabic poetry in English. I need to learn how to analyze a poem to translate it. I don't know the method of translation that I should use in translating poetry. Participant \# 22 added, I ask myself, how can I improve my translation? I can usually think of increasing my opportunities for adequate training. Training that is based on using my critical and creative abilities. Furthermore, the data analysis of the participants' responses resulted in generating emergent themes that led to better understanding of the causes of their problems. Table 4 shows these emergent themes. 
Table 4. Emergent themes of the qualitative data

\begin{tabular}{lc}
\hline Emergent Themes & Percentage of participants \\
\hline Ambiguity and untranslatability & 71 \\
Problems using equivalence & 66 \\
Difficulties transferring aesthetic message & 91 \\
Difficulties in translating images and symbols & 86 \\
Problems in choosing a method of translation & 73 \\
Lack of training & 97 \\
Ineffective teaching methodologies & 89 \\
\hline
\end{tabular}

As displayed in Table 4, the emergent themes that refer to students' problems in literary translation include lack of training (97\%); difficulties in transferring aesthetic message (91\%); using ineffective teaching methodologies (89\%); problems translating images and symbols (86\%); difficulties in selecting the most appropriate translation method (73\%); ambiguity and untranslatability (71\%); and difficulties in using equivalence (66\%). Regarding the emergent themes of the appropriate solutions as the participants reported, Table 5 shows the themes.

Table 5. Emergent themes for solving literary translation problems

\begin{tabular}{lc}
\hline $\begin{array}{l}\text { Emergent Themes } \\
\text { participants }\end{array}$ & Percent of \\
\hline Use cognitive-based teaching methodologies & 96 \\
Enhance students' creative skills & 84 \\
Link levels of linguistic analysis to translation practice & 86 \\
Add more courses in literary translation & 98 \\
Develop critical thinking & 83 \\
Use effective criteria for evaluating translation quality & 81 \\
\hline
\end{tabular}

As Table 5 shows, six themes emerged from the qualitative data analysis, regarding solutions to solve the students' problems in literary translation. These themes are: increasing the courses of literary translation (98\%), using cognitive-based teaching methodologies (96\%); linking levels of linguistic analysis to translation practice (86\%); enhancing students' creative skills (84\%); developing student' critical thinking (83\%); and using effective criteria for evaluating translation quality $(81 \%)$. Thus, the emergent themes indicate that the instructors should use cognitive teaching methodologies in teaching literary translation.

\subsection{Textual Corpus Results}

The results of coding the corpus data revealed an infinite number of categories into which the units of meaning of the selected literary texts and their translations were classified. The analyses of the syntactical, semantic, and lexical categories of the SL and TL of the texts helped in describing the content, structure, and functions of the messages contained the literary texts. Data analyses revealed that language differences affect the process of translation. Identifying such differences is important to determine the source texts' meaning and reconstruct it appropriately. The generic analysis is also pertinent to selecting the appropriate translation strategies. Textual analysis required the synthesis of four cognitive aspects in each literary text: phonology, syntax, semantic, and pragmatic. At the phonological level, data showed the distinctions in meaning that can be made on the basis of sounds, especially in poetry. Analysis of phonology referred to discriminating between two words that sound similar such as words with similar phonemes. At the phonological level, Wordsworth's (1884) nature poems showed how the poet conveyed various images through the rhyming words and the repetition of sounds. For example, in his poem Intimations of Immortality, he used the following images: The rainbow comes and goes, sunshine is a glorious birth, there hath pass'd away a glory from the earth, now, while the birds thus sing a joyous song, and while the young lambs bound. Using the symbols of colors, sounds, and movement is a poetic device that makes the poems vivid, creating a contrast between sound and sight. On the other hand, textual analysis showed that T.S. Eliot (2004) used symbolic images as linguistic devices to violate linguistic norms, i.e. the standard poetic utilization of language, to create disillusioned and nostalgic effects on his readers. For example, in his poem, The Love Song of Alfred Prufrock, he created such symbolic 
images as: I have measured out my life with coffee spoons, yellow fog that rubs its back upon the window-panes, licked its tongue into the corners of the evening, Shall I part my hair behind? Do I dare to eat a peach? by combining not only sounds and sight, but also breaking up the grammatical rules through a mixture of affirmative, interrogative, and infinitive sentences in the present, past, and perfect tenses.

At the morphological level, words are constructed to have either lexical or grammatical functions. For example, in prose literary texts, derivational morphology affects the meaning of words and their functions. Words such as patient, outpatient, trial, retrial, dark, darkness, flex, flexible are different in various contexts. At the syntax level, the meanings of words change according to their combination with each other to form phrases or sentences. Changing word order or adding or subtracting words from sentences change their meanings. For instance, data analysis showed in Pride and Prejudice, by Jane Austen (2014), the following sentences: A long dispute followed this declaration; but Mrs. Bennet was firm: it soon led to another; and Mrs. Bennet found, with amazement and horror, that her husband would not advance a guinea to buy clothes for his daughter. The relationship among the words in these sentences are determined by word order. However, a change of word order, or making a substitution whether by addition or omission can distort the meaning. At the semantic level, textual analysis showed that meaning is not dependent or static. A state of cohesion, i.e. surface relations which link words and expressions together, and coherence, i.e. conceptual relations which underlie the surface text, should exist to convey the meaning of the text. Therefore, implied meaning, symbols, allegories, images, etc. need to be clearly understood to provide accurate and adequate translation. In this respect, corpus data analysis showed the following example from The Road from Colonus by E.M. Forster (2013): At the present moment, here he was in Greece, and one of the dreams of his life was realized. Forty years ago he had caught the fever of Hellenism, and all his life he had felt that could he but visit that land, he would not have lived in vain. As the underlined words reveal, the semantic choices are in harmony with the surface structure and the deep meaning underneath such structure. In the phrase 'one of the dreams of his life was realized', the choice of the passive voice was realized adds a lot to the meaning and leaves the reader wondering when and how it was realized. This same meaning is perceived better in the sentence 'Forty years ago he had caught the fever of Hellenism'. The metaphorical use of the expression 'caught the fever' is harmonious and an apt way of expressing his strong love for Greece and the Hellenic culture and paves the way for his subsequent visit to Greece. When translating this extract into Arabic, semantic choices are important since they determine adequacy to the original context. At the pragmatic level, understanding the use of language in specific situations is essential to convey the source language message. For instance, data analysis showed that translating the following extract from The Necklace by Guy de Maupassant (2006), students should know the concept of "implicature" introduced by Grice (1991) and used in the pragmatics subfield of linguistics. Students should also know the application of pragmatic equivalence as teachers underline the words that refer to the implied meanings in words such as pleasure, company, delighted, trouble, one, big, and affair:

"The Minister of Education and Madame Ramponneau request the pleasure of the company of Monsieur and Madame Loisel at the Ministry on the evening of Monday, January the 18th."

Instead of being delighted, as her husband hoped, she flung the invitation violently across the table, murmuring:

"What do you want me to do with this?"

"Why, darling, I thought you'd be pleased. You never go out, and this is a great occasion. I had tremendous trouble to get it. Everyone wants one; it's very select, and very few are given to clerks. You'll see all the really big people there."

She looked at him out of furious eyes, and said impatiently: "And what do you suppose I am to wear at such an affair?"

Data analysis showed that the ambiguity of this extract can be explained through translating the underlined words carefully. So, the words pleasure, company, delighted, trouble, and affair convey different meanings if they are translated singly. The sentence You'll see all the really big people there if translated literally, it will distort the meaning while the meaning here is: you will meet honorable people. The word 'big' in Arabic does not mean important: it only means physically big or huge. Thus, the analysis of the linguistic levels indicates that applying pragmatic equivalence when translating literary texts helps in transferring the meaning, and that the aspects that affect pragmatic equivalence include cohesion, coherence, and inference. Adequate translation requires analyzing various levels of source text to understand the meaning of single words and expressions, grammatical categories, and cultural contexts in order to identify various kinds of emotive and stylistic connotations. Data analysis also showed the dimension of language based on Hallidy's model as shown in Figure 6. 


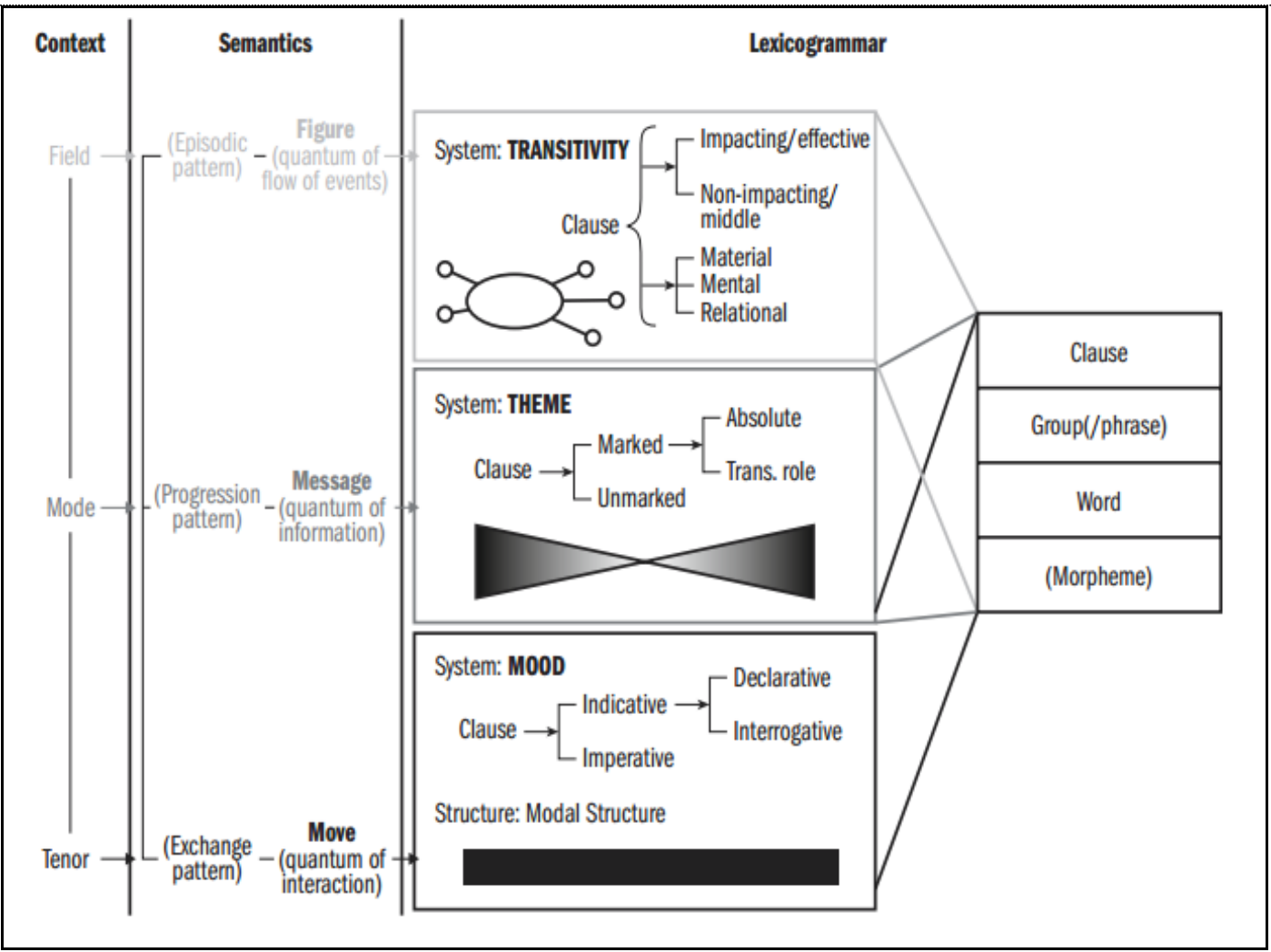

Figure 6. Halliday's dimension of language

As displayed in Figure 6, Halliday's model is comprehensive. It presents the entire picture of language which helps in understanding the dynamic of the semiotic system and the organization of meaning in the grammar. Halliday identified three variables in any context that systematically determine a text's register, and affect language choices. Theses variables are: the field which points at the language and the purposes of the text; the tenor which refers to the participants in the language event, and their relationship; and the mode which indicates how language is written (or spoken). Hence, data analysis results showed that cognitive teaching methodology encourages students to be involved in a number of mental activities to analyze the text before translating it, confirming the answer of the second question of the current research that there is a relationship between the linguistic levels of literary texts (lexical, syntactic, and semantic) and the quality of literary translation (functional adequacy, specialized content, and dynamic equivalence. Previous research results are compatible with the current study findings. For example, Argamon et al. (2007) concluded that using functional lexical features helped in stylistic text classification. Buhler and Goodwin (2011) stressed the representational function of language and its impact on understanding direct and implied meaning. Rydning and Lachaud (2010) confirmed that different levels of linguistic analysis reduced polysemy during the process of understanding the text and increased creativity during the process of translation. Sapargul and Sartor (2010) asserted that using the grammar translation techniques was effective in increasing language proficiency and improving translation skills. Shirinzadeh and Mahadi (2014) concluded that linguistic analysis helped in using the expansion strategies in making untranslatable stanzas of poetry translatable.

Regarding the third research question on how teachers can incorporate literary translation theories into cognitive teaching methodologies, data analysis showed that incorporating Bloom's, (Bloom et. al, 2000) cognitive domains into the linguistic approach of analysis helped in recognizing multiple levels of understanding and analyzing the literary texts. The six major cognitive domains include knowledge, comprehension, application, analysis, synthesis, and evaluation. In this cognitive taxonomy, the knowledge domain refers to recalling information while the understanding domain refers to the interpretation of instructions and problems. The application domain represents the use of a concept in a new situation which is implemented through the constructing, discovering, manipulating, modifying, producing, relating, and problem-solving processes. The domain of analysis explains the mental process of separating certain concepts into component parts in order to understand their structures. The analysis domain is employed to differentiate between facts and inferences. The synthesis domain refers to building a structure from diverse elements. The evaluation domain explains how to assess the value of the product. Thus, the first phase of using Bloom's cognitive taxonomy in teaching literary translation is collecting knowledge of source text, which includes information about the author, the historical background of the text, and information about the target language readership. For example, translating Shakespeare's plays Richard II, and Richard III, King John, Henry VI, Julius Caesar, and Coriolanus requires knowledge about the history of England and the history of Rome. The second phase is comprehension of source literary texts which focuses on understanding the concepts and the structure of the text and its literary devices. The third phase is analysis of the source text, which refers to the implementation of knowledge through manipulating, modifying, producing, and problem-solving processes. According to Newmark (1995), the macrotextual and microtextual analyses of the source and the target texts are important because such analyses include all the criteria that the translators need to understand the texts and decode their messages. The macrotextual analysis provides information about all the units that constitute the meaning including the historical and cultural factors that influence the literary text settings. The 
microtextual analysis is important for understanding the linguistic segments of literary texts and how linguistic shifts are made. For example, translating the following extract from The Last Leaf by O. Henry (1997): I have something to tell you, white mouse," Sue said. "Mr. Behrman died of pneumonia today in the hospital. He was ill only two days. The doorkeeper found him the morning of the first day in his room downstairs helpless with pain. His shoes and clothing were wet through and icy cold. They couldn't imagine where he had been on such a dreadful night, requires cognitive skills to select the appropriate translation strategies to solve the problems. In this extract, together with the other abovementioned examples, Newmark's (1988) translation strategies can be applied to solve the translation problems. These strategies include: (a) conducting componential analysis of the text, which requires translating SL word into two or more TL words by distributing its semantic components over a larger TL area; (b). distinguishing the meaning of two collocated SL synonyms; (c) analyzing the content of one or more SL words within a series of words; (d) filling in gaps in the TL lexis due to cultural differences; ( e) analyzing neologisms; (f) analyze theme words, which need extended definitions; and (g) reducing the metaphors which have two or more meanings.

Moreover, the phase of analysis of the source text, which refers to the implementation of knowledge through manipulating processes is linked to the fourth phase of synthesis of the source texts, which means reconstructing the whole text. At this stage, students should be able to rearrange the text to render the meaning. The fifth phase is the reconstruction of the source text, when students are able to recode the messages of the original texts. The final phase is the assessment of the target text. The assessment domain provides evidence about the quality of the final translation. Teachers should train students to compare and contrast different translations of the same text. Using parallel translations is also helpful for students to acquire the self-correction skills that are integral in the assessment process. In this respect, Nida (1964) identified three basic parameters in the assessment process, which include comprehension, correctness, and adequacy. To illustrate the whole picture of the suggested cognitive model, the following is an extract from Akenfield by Ronald Blythe (1969) to show how teachers can use the cognitive approach in the classroom applying its six phases:

There were ten of us in the family, and, as my father was a farm laborer earning thirteen shillings a week, you can just imagine how we lived. I will tell you the first thing which I can remember. It was when I was three-about 1899 . We were all sitting round the fire waiting for my solider brother to come home-he was the eldest boy in the family. He arrived about six in the evening and had managed to ride all the way from Ipswich station in a milk-cart. The young man came in, and it was first time I had seen him. He wore a red coat and looked very lively. Mother got up and kissed him, but father just sat and said: "how are you?" Then we had tea, all of us staring at my brother. It was dark; it was wintertime. A few days later he set off again, and my mother stood in the middle of the road, watching. He was going to fight in South Africa. He walked smartly down the lane until his red coat was no bigger than a poppy. Then the tree hid him. We never saw him again. He was twenty-one.

Teachers can simplify literary texts as a first stage to train students to appreciate the texts' aesthetic value. Students will learn that translating literary texts does not only depend on knowing the meaning of the difficult words, but also on understanding the symbolic message of the author. While the simplified text does not include difficult words, each sentence conveys a symbolic meaning that leads up to the sad ending, such as the following sentences: 'you can just imagine how we lived', 'Mother got up and kissed him, but father just sat and said: how are you?', 'It was dark; it was wintertime', 'He walked smartly down the lane', 'his red coat was no bigger than a poppy',...etc. Keeping the information about the boy's age until the last sentence of the passage also has an emotional function that teachers should discuss with students. Applying the cognitive approach to translate this extract from Akenfield requires teachers to employ the following steps: Phase One: Knowledge; engage students to collect information about the author Ronald Blythe and the circumstances of writing his novel. Students will learn that the author was born in Acton, Suffolk, an English agricultural village. He was the eldest of six children and that his father was a farmer who fought in World War I. Blythe himself served during World War II. This information is important as it explains the atmosphere of the novel, the intention of the author, and the literary images and symbolism used in the story such as the colors "red" and the image of the "poppy" flowers; Phase Two: Comprehension; students should read the passage generally and closely. The purpose of general reading is to understand the main ideas of the text, the setting, the plot, and the characters. The purpose of close reading is to help students understand the structure, the implied meaning, and the literary devices; Phase Three: Analysis; teachers should engage students in discussions to conduct referential and textual analysis of the passage. The analysis should also include the functions of the punctuation marks. The referential analysis helps students to understand the references that the author made to create the setting of his novel. Words such as "red coat", and "poppy" also have a symbolic meaning. Students analyze the meaning of all the symbols used such as the color red which refers to blood, and therefore death. The poppy flower reminds us of the World War I which took place in the poppy fields of Flanders. Red poppies symbolize the remembrance of the soldiers who died during wartime. Students should identify the translation problems and the strategies for solving them. Applying Newmark's strategies, students can use definition, or footnotes to clarify the symbols in this text. Using footnotes is more appropriate herein to explain the symbolic meaning of the poppies so as to keep the readers' attention focused on the story ending. Teachers should also discuss with students the translation methods for literary texts; Phase Four: Synthesis; students continue the class discussions to synthesize the passage and put together the information they analyzed in the previous phase in order to build the new linguistic units that they will use in the target language; Phase Five: Reconstruction; students begin to recode the messages of the original texts, refine their literal translation, and produce the text according to the linguistic features of the target language; and Phase six: Assessment; teachers engage students in class discussion to comment on each other's final translations. Students should be able to provide a critique about their translations. Such discussions 
enable students to correct their mistakes and edit the final translations. As such, students learn how to penetrate into the complexities of a literary text, as shown in Figure 7.

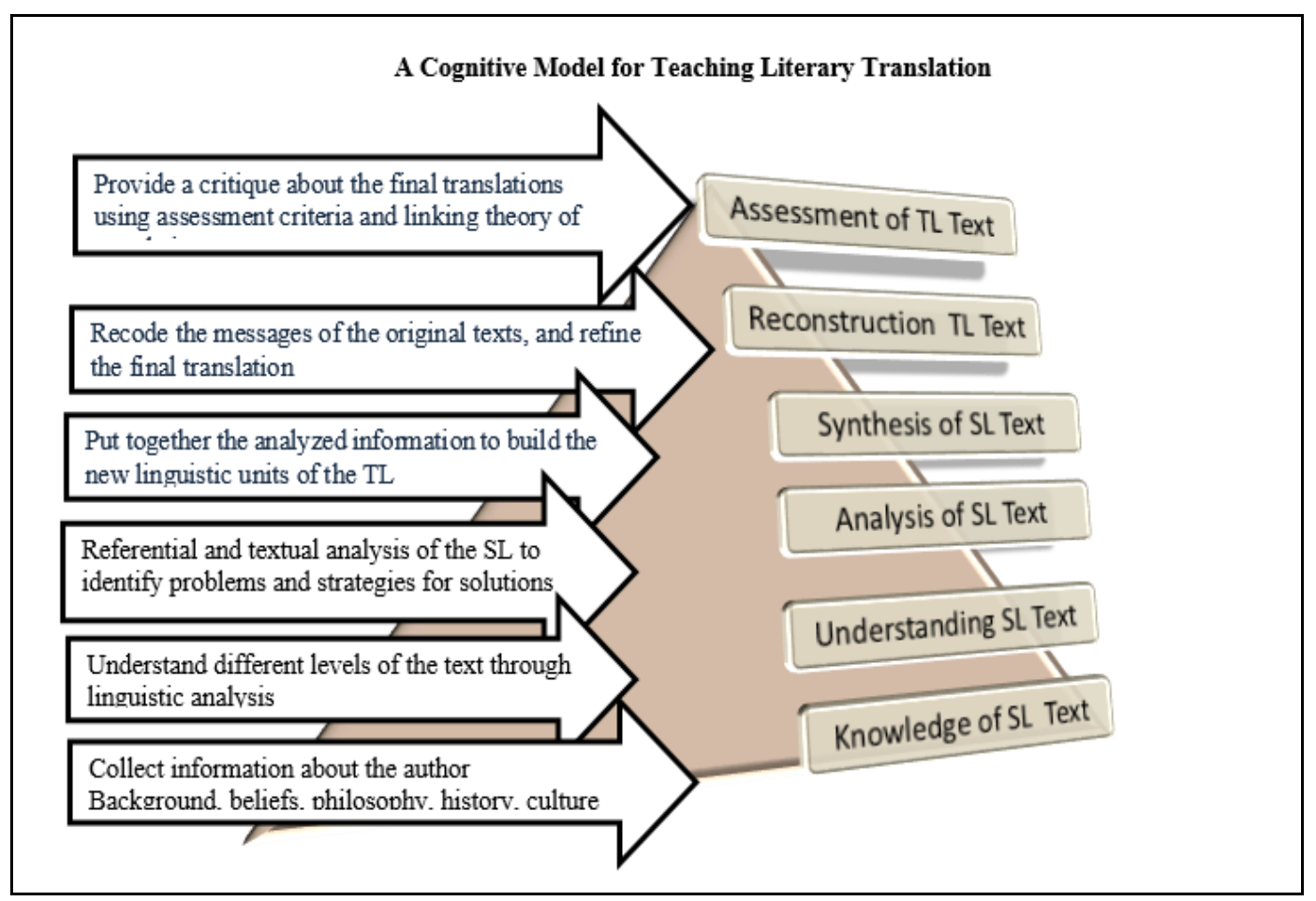

Figure 7. A cognitive for teaching literary translation

As displayed in Figure 7, the cognitive approach can help students develop translation skills. The assessment phase is also integral in the cognitive approach, to engage students in assessing their own learning. When students apply the translation assessment concepts such as accuracy, adequacy, relevancy, coherence and cohesion, they can improve the quality of their translation. Thus, the findings of the current research are parallel with those of numerous previous studies (Bransford, Brown, \& Cocking, 2000; Moghadas \& Sharififar, 2014; Munoz, 2010; Risku, 2012; Rojo, 2015; Schaffner, 2004; Schwieter \& Ferreira, 2014; Shreve \& Angelone, 2010 ; Yingxue, 2013 ; Zasyekin,. 2010). Such studies were in line with each other, indicating the positive effect of integrating cognitive approaches into teaching literary translation.

\section{Recommendations}

Based on the findings of this research, the first recommendation is that integrating Newmark's theory into Bloom's cognitive approach can have positive impacts on students' creativity and quality of translation. Blooms's taxonomy includes procedural patterns for developing mental abilities that should be enhanced in the translation classroom, as shown in Figure 7. Cognitive approaches can help graduate students by training them to meet the requirements of quality translation. Translation training should focus on a number of effective strategies including: understanding how theory and practice are interdependent; analyzing the source text at different linguistic levels; adhering to the rules of the target language; rendering the meaning of the text accurately; and achieving dynamic-pragmatic equivalence. The second recommendation is to encourage teachers to carry out similar studies in other universities to paint a clearer picture for integrating Newmark's theory into cognitive teaching methods. The third recommendation is to link linguistic generic analysis to the cognitive teaching approach to motivate students to perceive the processes of literary translation as continuous mental activities that require developing language sensitivity and style eloquence. The fourth recommendation is to increase the courses of literary translation to allow students to have adequate training. The fifth recommendation is to provide professional programs to help teachers develop cognitive-based teaching methodologies.

\section{Conclusion}

The current research concentrated on the need to expand the perimeters of translation studies to pay more attention to literary translation. The demand for literary translation is growing due to the increase of the publications of classical and modern works of art. However, lack of training, and ineffective teaching strategies do not help students to acquire advanced translation skills. Therefore, the purpose of this case study was to explore, analyze, and classify the difficulties that graduate students face while translating different literary genres. Quantitative and qualitative data were collected from a focus group of participants who study translation at the College of Languages and Translation, IMAMU University. Data analysis indicated that students need to improve their cognitive skills to produce a translation of high quality. The research findings of the present study provided evidence that there is a positive correlation between cognitive-based teaching methods and students' performance in literary translation. The research findings also showed that because translation involves a number of complex mental activities that require using higher-order thinking, teachers can integrate translation theories into the cognitive model as a way to train students to use a systematic approach that links different levels of linguistic analysis to translation strategies. This approach depends on collecting 
knowledge about the source texts, comprehending source texts through general and close reading, conducting textual and referential analysis, synthesizing the text literary components, reconstructing the target text creatively, and assessing the quality of the final translations objectively. Teachers can use the suggested cognitive model, presented in this research, which integrates Newmark's theory into Bloom's cognitive taxonomy, to help students strengthen their cognitive and metacognitive abilities, and use translation strategies to identify and solve the translation problems in literary texts. The suggested Newark-Bloom model provides criteria that include self-correction, parallel evaluation, and objective critique to assess the accuracy and adequacy of the translations. Hence, the cognitive-based teaching methodologies are appropriate for helping students become competent translators.

\section{References}

AlBzour, B. A. (2016). Cognitive systematicity of semantic change: cross-linguistic evidence. International Journal of Applied Linguistics and English Literature, 5(3), 91-98. doi:10.7575/aiac.ijalel.v.5n.5p.62.

Argamon, S., Whitelaw, C., Chase, P., Hota, S., Garg, N., and Levitan, S. (2007). Stylistic text classification using functional lexical features. Journal of the American Society for Information Science and Technology 58(6), 802-822. http://onlinelibrary.wiley.com/doi/10.1002/asi.v58:6/issuetoc

Austen, J. (2014). Pride and prejudice. (New edition). New York: Create Space Independent Publishing Platform Baker, M. (2000). Towards a methodology for investigating the style of a literary translator. Target, 12(2), $241-266$.

Baker, M. (2005). Contextualization in translator and interpreter-mediated events. New York: Elsevier Baker, M. (2011). In other words: A course book on translation (2 nd. ed.). New York: Routledge.

Barnstone, W. (1995). The Poetics of translation. CT, New Haven: Yale University Press. Bassnett, S. (2002). Translation studies (3rd ed.). London: Routledge.

Biber, D., \& Conrad, S. (2009). Register, genre, and style. New York: Cambridge University Press.

Bloom, B. S., Engelhart, M. D., Hill, W. H., \& Krathwohl, D. R. (2000). Taxonomy of educational objectives: The classification of educational goals, handbook I: cognitive domains. (New edition). New York: David McKay Company, Inc.

Blythe. R. (1969). Akenfield. New York: Pantheon Books.

Boase-Beier, J. (2011). A critical introduction to translation studies. London: Continuum International Publishing Group Ltd.

Bransford, J.D. Brown, \& Cocking, R. R. (2000). (ed.). How People learn: Brain, mind, experience, and school: Commission on Behavioral and Social Sciences and Education, National Research Council. Washington, D.C.: National Academy Press.

Buhler, K. \& Goodwin, D. F. (2011). Theory of language: The representational function of language. New York: John Benjamin's Publishing Company.

Chanda, I. (2012). Metaphor translation as a tool of intercultural understanding. Comparative Literature and Culture, 14(4), 1-9. http://dx.doi.org/10.7771/1481-4374.1996

Creswell, J. (2013). Research design; qualitative and quantitative and mixed methods approaches (4 th. ed.). London: Sage.

Dean, R. J. (2010). The effects of cognitive process and decision making training in reading experience on meaningful learning with underachieving college students. ProQuest LLC, Dissertation, University of Massachusetts Lowell.

DiYanni, R. (ed.) (2002). Plato: poetry and inspiration (translated by Benjamin Jowett), in Literature: Reading fiction, poetry, and drama. New York: McGraw-Hill Publishing Co.

Dryden, J. (1987). The major Works (edited by Keith Walker). Oxford: Oxford: Oxford University Press.

Eggins, S. (2004). Introduction to systemic functional linguistics (2 nd. ed.). New York: Continnum.

Eliot, T.S. (2004). Complete poems and plays. New York: Faber \& Faber.

Enani, M.M.(2000). On translating Arabic: A cultural approach. Cairo: G.E.B.O.

Forster, E.M. (2013). The E.M. Forster collection: Classic works. (New edition). New York: Waxkeep Publishing.

Gee, J. P. \& Handford, M. (2013). The Routledge handbook of discourse analysis: New York: Routledge.

Grice, P. (1991). Studies in the way of words. Cambridge : Harvard University Press.

Grice, P. \& Baker, J. (2011). The conception of value. Oxford: Oxford University Press

Grossman, E. (2011). Why translation matters. CT, New Haven: Yale University Press.

Gutt, E.A. (2010). Translation and relevance: Cognition and context (2 nd. ed.). New York: Routledge.

Halliday, M. A. K. (1985). An introduction to functional grammar. London: Arnold.

Halliday, M.A. K , (1989). Language, context, and text: Aspects of language in a social-semiotic perspective (2nd ed.).

Oxford: Oxford University Press. 
Halliday, M.A.K , (2004). An introduction to functional grammar (4 th. ed.). New York: Routledge

Halliday, M.A.K., \& Matthiessen, C. (2013). Halliday's introduction to functional grammar. New York: Routledge.

Henry, O. (1997). 100 Selected stories. (Reprint). New York: Wordsworth Editions. House, J. (2014). Translation quality assessment: Past and present. New York: Routledge.

Howlett, C.; Ferreira, J.; Blomfield, J. (2016). Teaching sustainable development in higher education: Building critical, reflective thinkers through an interdisciplinary approach. International Journal of Sustainability in Higher Education, 17(3), 305-321.http://dx.doi.org/10.1108/ijshe-07-2014-0102

Jae, J. S. (2005). The translatability-universals connection in linguistic typology: Much ado about something. Babel, 51(4), 308-322. http://dx.doi.org/10.1075/babel.51.4.03son

Jakoboson, R. (1967). On linguistic aspects of translation. In On Translation, ed. R.A. Brower.Cambridge: Harvard University Press.

Jakoboson, R. (1990). Language in literature. New York: Belknap Press.

Jakobson, R. (2000). On linguistic aspects of translation. Translated by Harry Zohn in Translation Studies Reader. Ed. Lawrence Venuti. London: Routledge.

Jakoboson, R. (2011). Fundamentals of language (New edition). Charleston, SC: Nabu Press.

Jones, M. H. (2014). The beginning translator's workbook: Or the ABC of French to English translation (Rev.ed.). Lanham, MD: University Press of America.

Kasparek, C. (1987). The translator's endless toil. The Polish Review, 2(3), 84.

Kenesei, A. (2010). Poetry translation through reception and cognition: The proof of translation is in the reading (New Edition). UK: Cambridge: Cambridge Scholars Publishing.

Kussmaul, p. (1995). Training the translator. New York: John Benjamins Publishing Co. Landers, C.E. (2001). Literary translation: A practical guide. New York: Multilingual Matters.

Larson, M. (1998). Meaning-based translation: A guide to cross-language equivalence. Lanham, MD: University Press of America and Summer Institute of Linguistics.

Lefevere. L. (1992). Translating literature: Practice and theory in a comparative literature context. New York: The Modern Language Association of America.

Lihua, Y. A. N. G. (2014). Treatment of cultural differences in translation. Studies in Literature and Language, 8(1), 39-42. 10.3968/j.sll.1923156320140801.2941

Madkour, M. (2011). Multiple intelligences and language acquisition: A qualitative study and application of Howard Gardner's theory of multiple intelligences. New York: Barnes \& Nobles.

Martin, J. R., \& Rose, D. (2007). Working with discourse: Meaning beyond the clause. New York: Continuum

Martin, J. R., \& White, P. R. (2005). The language of evaluation: Appraisal in English. New York: Palgrave.

Maupassant, G. (2006).The complete works of Guy de Maupassant: Short stories. (New edition). New York: Book Jungle.

Moghadas, S. M. \& Sharififar, M (2014). A Model for cognitive processes of neologisms translation. International Journal of English Langage \& Translation Studies, 2(1),04-19. http://www.eltsjournal.org/

Munday, J. (2012). Introducing translation studies: Theories and applications. New York: Routledge.

Munoz M. R. (2010). On paradigms and cognitive translatology. In G. M. Shreve \& E. Angelone (Eds.), Translation and cognition (pp. 169-89). Amsterdam, Netherlands: John Benjamins.

Newmark, P. (1988). A textbook of translation. London and New York: Prentice Hall International (UK) Ltd.

Newmark, P. (1998). More paragraphs on translation. Clevedon: Multilingual Matters Ltd.

Nida, E. A. (1964). Toward a science of translating. Leiden: E.J. Brill.

Nida, E. \& Taber, Taber, C.R. (1969). The theory and practice of translation, with special reference to Bibletranslating. Leiden: Brill.

Nida, E. \& Taber, C. R. (1974). The theory and practice of translating (New edition). Leiden: Brill. Nurmi, A. (2016). Minority voices in literary fiction: A case study of translating multilingual practices. Multilingua: Journal of Cross-Cultural and Interlanguage Communication, 35(2), 227-249. http://dx.doi.org/10.1515/multi-20150035

Oxford Dictionary. (2015). Figurative speech. Oxford: Oxford University Press.

Pantopoulos, I. (2012). Two different faces of Cavafy in English: A corpus-assisted approach to translational stylistics. International Journal of English Studies, 12(2), 93-110. http://revistas.um.es/ijes/article/view/161771

Parrish, P. E. (2006). Aesthetic principles for instructional design. Paper presented for AECT Annual Conference, October, 2006, University Corporation for Atmospheric Research. 
Pym, A. (2010). Exploring translation theories. New York: Routledge.

Qualitative Software Research International (QSR). (2016). NVivo version 10. Retrieved from the URL http://www.qsrinternational.com/

Reiss, K. (2015). Translation criticism- potentials and limitations: Categories and criteria for translation quality assessment. New York: Routledge.

Risku, H. (2012). Cognitive approaches to translation. The Encyclopedia of Applied Linguistics, 5, 110.http://onlinelibrary.wiley.com/book/10.1002/9781405198431

Rojo, A. (2015). Translation meets cognitive science: The imprint of translation on cognitive processing. Multilingua: Journal of Cross-Cultural and Interlanguage Communication, 34(6), 721-746.http://dx.doi.org/10.1515/multi-20150035

Rydning, A. F., \& Lachaud, C. M. (2010). The reformulation challenge in translation: Context reduces polysemy during comprehension, but multiplies creativity during production. In G. M. Shreve \& E. Angelone (Eds.), Translation and cognition (pp. 85-108). Amsterdam, Netherlands: John Benjamins.

Sapargul, D., \& Sartor, V. (2010).The trans-cultural comparative literature method: Using grammar translation techniques effectively. English Teaching Forum, 48(3), 26-30.

https://americanenglish.state.gov/files/ae/resource_files/48_3_5_-sapargul_sartor.pdf

Schaffner, C. (2004). Metaphor and translation: some implications of a cognitive approach. Journal of pragmatics, 36(7), 1253-1269. http://dx.doi.org/10.1016/j.pragma.2003.10.012

Schwieter, J. W. \& Ferreira, A. (2014). The development of translation competence: Theories and methodologies from psycholinguistics and cognitive Science. Cambridge: Cambridge Scholars Publishing. Scott, C. (2004). Back translation: Same questions, different continent. London: Association of Translation Companies. Shi, X. (2014). The strategy of metaphor translation: Domestication or foreignization. Theory and Practice in Language Studies, 4(4), 766-770. http://dx.doi.org/10.4304/tpls.4.4.766-770

Shirinzadeh, S., \& Mahadi, T. (2014).Using expansion strategies in making untranslatable areas of poetry translatable: Sa'di's Bustan as a case in point. English Language Teaching, 7(8), 39-52. http://dx.doi.org/10.5539/elt.v7n8p39

Shreve, G. M. \& Angelone, E. (2010). Translation and cognition. John Benjamins Publishing. Kent: Kent State University.

Shreve, G. M., Lacruz, I., \& Angelone, E. (2010). Cognitive effort, syntactic disruption, and visual interference in a sight translation task. In G. M. Shreve \& E. Angelone (Eds.), Translation and cognition (pp. 63-84). Amsterdam, Netherlands: John Benjamins.

Stubbs, M. (2001). Words and phrases: Corpus studies of lexical semantics. Blackwell Publishers Inc. Massachusetts.

Sun, S. (2012). Measuring difficulty in English-Chinese translation: Towards a general model of translation difficulty, $\mathrm{PhD}$ Dissertation, Kent State University. Retrieved from the URL http://search.proquest.com/docview/1039104230

The University of Kansas. (2015). Cognitive strategies. Retrieved from the URLhttp://www.specialconnections.ku.edu/?q=instruction/cognitive.

ToV Le, Q., \& Le, T. (2015). Applying Halliday's linguistic theory in qualitative data analysis. Qualitative Research Journal, 15(2), 135 - 146. doi.org/10.1108/QRJ11-2014-0059

Treffinger, D., Schoonover, P. \& Selby, E. (2012). Educating for creativity and innovation: A comprehensive guide for research-based practice. New York: Prufrock Press, Inc. Van, T. T. M. (2009). The relevance of literary analysis to teaching literature in the EFL classroom. English Teaching Forum 47(3), 2-9.

Venuti, L. (2012). The translation studies reader. London: Routledge.

Waldau, T. (2010). Metaphors and translation: A study of figurative language in the works of Astrid Lindgren Stockholm: Mid Sweden University, Department of Humanities (English Studies).

Wilson, B. G. (2005). Broadening our foundation for instructional design: Four pillars of practice. Educationa Technology,45(2),10-16.

Wordsworth. W. (1884). Ode: Intimations of immortality from recollections of early childhood. New York: Library of Congress.

Yin, R. K. (2014). Case study research: Design and methods. (5th ed.) . London: Sage.

Yingxue, Z. (2013). The motivation of problem-based teaching and learning in translation. English Language Teaching, 6(4), 120. http://dx.doi.org/10.5539/elt.v6n4p120

Yinhua, X. (2011). Equivalence in translation: Features and necessity. International Journal of Humanities and Social Science, 1(10), 1-3. http://www.ijhssnet.com/journals/Vol_1_No_11_Special_Issue_August_2011/19.pdf

Zasyekin, S. (2010). Translation as a psycholinguistic phenomenon. Journal of Psycholinguistic Research, 39(3), 225234. http://link.springer.com/article/10.1007\%2Fs10936-009-9134-2 